NOTE

\title{
First report of spontaneous chytridiomycosis in frogs in Asia
}

\author{
Yumi Une $^{1,5, *}$, Sho Kadekaru${ }^{1}$, Kenichi Tamukai $^{2}$, Kouichi Goka $^{3}$, Toshiro Kuroki ${ }^{4}$ \\ ${ }^{1}$ Laboratory of Veterinary Pathology, Azabu University, 1-17-71 Fuchinobe, Sagamihara, Kanagawa 229-8501, Japan \\ ${ }^{2}$ Denenchofu Animal Hospital, 2-1-3 Denenchofu, Ota-ku, Tokyo 145-0071, Japan \\ ${ }^{3}$ National Institute for Environmental Studies, 16-2 Onogawa, Tsukuba, Ibaraki 305-8506, Japan \\ ${ }^{4}$ Kanagawa Prefectural Institute of Public Health, 1-3-1 Shimomachiya, Chigasaki, Kanagawa 253-0087, Japan \\ ${ }^{5}$ Present address: Laboratory of Veterinary Pathology, School of Veterinary Medicine, Azabu University, 1-17-71 Fuchinobe, \\ Sagamihara, Kanagawa 229-8501, Japan
}

\begin{abstract}
This is the first report of amphibian chytridiomycosis in Asia. We discovered a lethal outbreak in Japan, among 45 exotic frogs from 18 species kept for breeding by a private owner. Of these 45 frogs, 16 died and another 7 were found to be infected by chytrid fungus Batrachochytrium dendrobatidis $(B d)$ but survived after treatment. $B d$ was detected in frogs from 9 species (Lepidobatrachus laevis, Ceratophrys cornuta, C. cranwelli, C. ornata, C. calcarata, Chacophrys pierotti, Occidozyga lima, Leptodactylus pentadactylus and Plethodontohyla tuberata).
\end{abstract}

KEY WORDS: Chytridiomycosis $\cdot$ Batrachochytrium dendrobatidis $\cdot$ Captive frog $\cdot$ Japan Resale or republication not permitted without written consent of the publisher

\section{INTRODUCTION}

Chytridiomycosis is an important emerging disease of amphibians caused by the newly identified chytrid fungus Batrachochytrium dendrobatidis $(B d)$ (Berger et al. 1998, Longcore et al. 1999, Skerratt et al. 2007, Young et al. 2007). It is not only a source of significant disease in both captive and wild amphibians, but also a major conservation concern worldwide because of its association with mass mortality and frog population declines, including the extinction of some species, in all major regions where amphibians occur except Asia, namely Africa, Oceania, North America, South America, and Europe (Speare \& Berger 2000, Bradley et al. 2002, Weldon et al. 2004, Lips et al. 2006, Hyatt et al. 2007). As a temperate country of middle latitude, with a steep geomorphology and fairly long geological isolation, Japan is inhabited by diverse endemic amphibians including a number of threatened taxa (Ota 2000). We confirmed the presence of chytridiomycosis for the first time in Japan in December 2006. This was also the first case reported in Asia. The present paper describes the nature of this outbreak in captive, exotic frogs, and warns of the presence of this highly pathogenic fungus in Japan.

\section{MATERIALS AND METHODS}

A lethal outbreak of chytridiomycosis was discovered in a collection of 45 aquatic and terratic frogs from 18 species belonging to a private owner in Tokyo. The owner had been breeding frogs since June 2005. All frogs were exotic and included frogs bred in captivity, directly imported frogs and wild-caught frogs.

Of the 45 frogs, 16 died between September 2006 and January 2007: 1 in September, 1 in January, and the remainder during November and December. The dead frogs were from 7 species; individuals from 2 more species in the same collection were later found to be affected by the disease. One affected Lepidobatrachus laevis suddenly became inactive, and died within 2 or $3 \mathrm{~d}$. Its body surface was covered with a large quantity of mucus. One Ceratophrys cornuta also died within a few days after 
having shown difficulty moving and excreted a small quantity of reddish feces before it died. One Leptodactylus pentadactylus, however, showed depression, inactivity and miosis for about 2 mo before it succumbed.

New frogs were introduced to the collection several times in the 4 mo before the fatalities occurred, but at least 5 of the dead frogs had been in the collection for more than $5 \mathrm{mo}$, i.e. before the introduction of new frogs. Almost all frogs were housed individually, but during weekly maintenance, the tools used were common to all. The owner had never previously experienced consecutive unexplained deaths of frogs in his collection. Of the 16 dead frogs, one each from the species Lepidobatrachus laevis, Ceratophrys cornuta, and Leptodactylus pentadactylus were submitted for pathological examination and molecular biological examination, using samples of skin and toe clip. Tissue samples of frogs were fixed in $10 \%$ neutral-buffered formalin, processed routinely in paraffin wax, sectioned at about $4 \mu \mathrm{m}$ thickness, and stained with hematoxylin and eosin, periodic acid Schiff's reaction and Fungiflora Y (Biomate, Tokyo, Japan; this stain shows high affinity for fungal cell wall polysaccharides). For transmission electron microscopy, formalinfixed tissue samples were post-fixed in $2.5 \%$ glutaraldehyde followed by $1 \%$ osmium tetroxide, then embedded in epoxy resin. Ultrathin sections were contrasted with uranyl acetate and lead citrate and were observed with transmission electron microscopy. For scanning electron microscopy, tissue samples were dehydrated by ascensional alcohol and t-butyl-alcohol and were coated with Au-Pd (particle diameter 2 to $10 \mathrm{~nm}$ ). Skin from 1 dead frog was observed using both electron microscopy techniques.

Skin samples of the 3 dead frogs which had been histologically examined, and swabs taken from the body surface of all 29 remaining frogs, were subjected to molecular biological examination (PCR) for chytrid fungus detection. DNA was extracted using protocols which include Proteinase $\mathrm{K}$ and dithiothreitol followed by QIAamp mini kit (Qiagen), or incubation at $95^{\circ} \mathrm{C}$ for $10 \mathrm{~min}$. In 10 of the 32 samples tested, a region of the 5.8S rRNA gene and the flanking internal transcribed spacer regions (ITS1 and ITS2) for Bd was amplified by PCR from the extracted DNA using the specific primers Bd1a and Bd2a (Annis et al. 2004). PCR assays were conducted with the procedure described in Goka et al. (2001). The thermal cycle conditions were an initial $9 \mathrm{~min}$ at $95^{\circ} \mathrm{C}$; followed by $30 \mathrm{~s}$ at $94^{\circ} \mathrm{C}, 30 \mathrm{~s}$ at $55^{\circ} \mathrm{C}$, and $30 \mathrm{~s}$ at $72^{\circ} \mathrm{C}$ for 30 cycles; and a final 7 min at $72^{\circ} \mathrm{C}$. PCR products were separated on $6 \%$ polyacrylamide gels, and bands of DNA fragments were made visible by ethidium bromide staining under UV light. Every second PCR product was sequenced twice from both forward and reverse by direct cycle sequencing using a MegaBACE1000 (GE Healthcare). The sequences were aligned with previously determined ITS sequences of $B d$ (DNA Database of Japan [DDBJ] accession no. AY997031; T. Y. James unpubl. data) using CLUSTAL W (Thompson et al. 1994).

\section{RESULTS}

PCR confirmed chytrid fungus infection in the 3 dead frogs tested. Of the 29 surviving frogs, 7 were also found to be infected by chytrid fungus but recovered and changed from positive to negative on PCR examination after treatment with antifungal drugs itranaconazole (bath of $0.01 \%$ itranaconazole for $10 \mathrm{~min}$ daily for $14 \mathrm{~d}$ ) and fluconazole (bath of $0.01 \%$ fluconazole for $24 \mathrm{~h}$ every other day, 10 times in total). The species of the frogs in which chytrid fungus infection was confirmed by pathological and molecular biological examination were Lepidobatrachus laevis, Ceratophrys cornuta, C. cranwelli, C. ornata, C. calcarata, Chacophrys pierotti, Occidozyga lima, Leptodactylus pentadactylus and Plethodontohyla tuberata.

\section{Macroscopic findings}

A large quantity of mucus and sloughed skin were found stuck to the body surface of the Lepidobatrachus laevis examined, but the Ceratophrys cornuta and Leptodactylus pentadactylus specimens showed no particular skin lesions.

\section{Microscopic findings}

Skin lesions showed similar characteristics in all frogs and were most prominent on the ventral abdomen, drink patch and digits, but the degree varied by species. The fungus grew in the superficial keratinizing epithelium, where various developmental stages of fungus were observed (Fig. 1). The mature zoosporangia with zoospores ranged from approximately 5.3 to $10.9 \mu \mathrm{m}$ in diameter. Immature fungi were observed as basophilic spherical bodies located near the epidermis and in deeper portions of the keratinized layer. Mature zoosporangium, some containing zoospores, were observed as round, flask- or pot-like forms with discharge tubes, and chytrid thalli, both empty and with faintly visible internal septation (colonial thallus) (Fig. 2). Thickening of the keratinized layer was severe in the Ceratophrys cornuta specimen, and the degree of infection was also highest. Degeneration of the epidermis, vacuolar changes of the epidermis accompanied with ballooning degeneration, hypereosinophilia and scattered single cell necrosis of ker- 


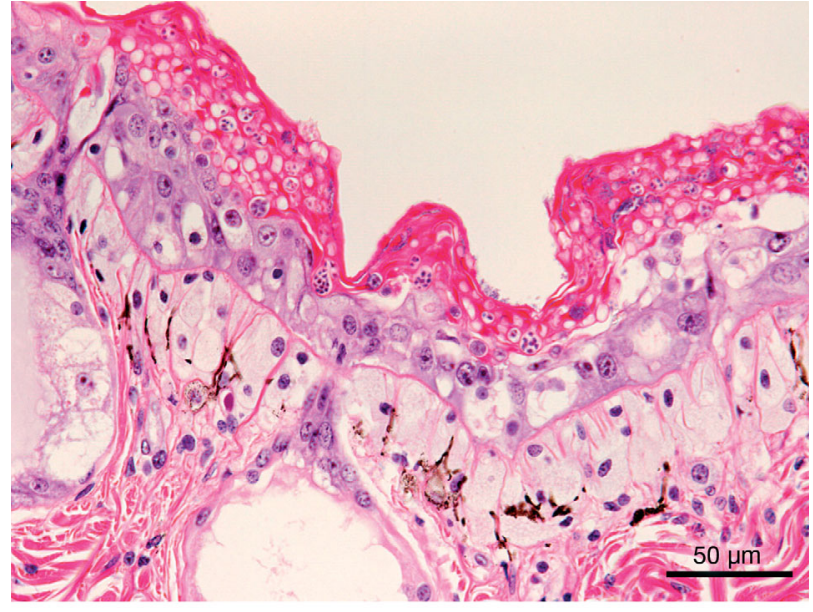

Fig. 1. Skin of Lepidobatrachus laevis. Chytrid fungus Batrachochytrium dendrobatidis at various developmental stages in the keratinized layers. Mayer's hematoxylin \& eosin stain

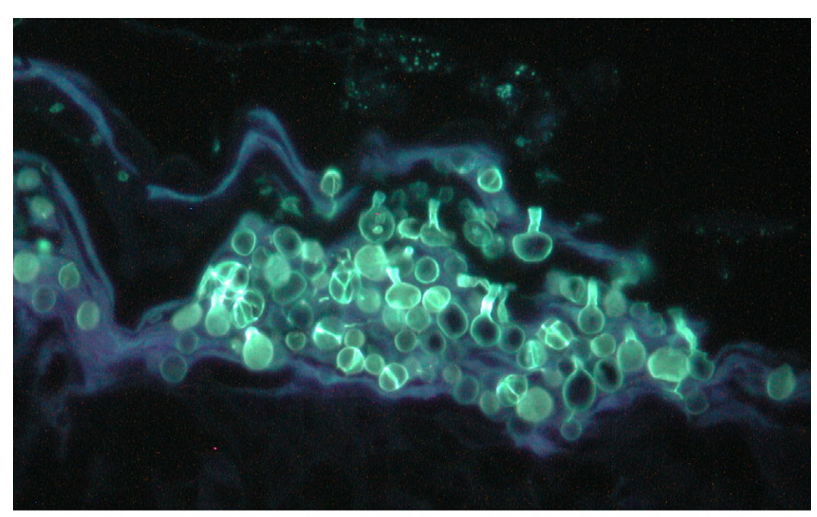

Fig. 2. Skin of Ceratophrys cornuta. Chytrid fungus Batrachochytrium dendrobatidis zoosporangia containing some zoospores, observed as round, flask-like forms with discharge tubes, and chytrid thalli. Fungiflora Y stain

atinocyte and mild edema in dermis without ulceration were observed. However, these degenerative changes were more advanced in the Lepidobatrachus laevis specimen than in the C. cornuta specimen. In the Leptodactylus pentadactylus specimen, the keratin layer was thin, and the degree of fungal infection was slight, but hyperplasis of the epidermis was advanced, with scattered lymphocyte infiltration.

With scanning and transmission electron microscopy, we confirmed the presence of characteristic fungi in the keratinized layers of infected frogs (Fig. 3). That is, scanning electron microscopy demonstrated that the chytrid thalli with discharge tubes protruded like a dome on the cutaneous surface. In transmission electron microscopy, chytrid thalli of various developmental stages were embedded in the keratin layer, and some zoosporangia also included bacteria.

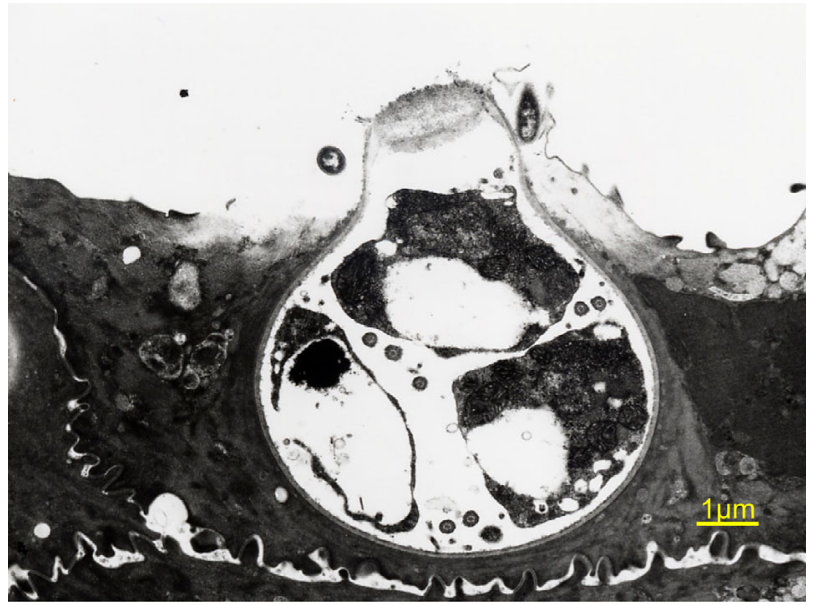

Fig. 3. Skin of Ceratophrys cornuta. Chytrid fungus Batrachochytrium dendrobatidis zoosporangium with plug and zoospores. Transmission electron micrograph.

\section{PCR findings}

We consistently obtained a single fragment of approximately $300 \mathrm{bp}$ from PCR amplification. In positive samples, all of the DNA fragment sequences were entirely consistent with the ITS1-5.8S-ITS2 region sequences from $B d$ registered in the DDBJ databank (accession number AY997031).

\section{DISCUSSION}

Diagnosis of chytridiomycosis is based on pathological findings, molecular biological findings and scanning and transmission electron microscopy (Berger et al. 1999). In the present case, characteristic histological findings including the flask-shaped zoosporangia and septate thalli of $B d$ were observed in keratinized layers of the skin of affected frogs. In addition, the genetic base sequence of a specific gene amplified from affected frogs by PCR accorded with that for $B d$ registered with DDBJ. Based on the above findings, we diagnosed the present case as chytridiomycosis, and believe it to be the first such confirmed case reported in Japan and in Asia.

The exact time when $B d$ invaded the private owner's frog collection is not clear. However, the owner had been breeding frogs continuously for 18 mo before the sudden outbreak of chytridiomycosis and had introduced a number of new frogs about 4 mo before, suggesting that these new frogs were the source of infection. We postulate that horizontal transmission occurred, since many frogs that had been in the collection for a long time were affected, while in the breeding environment, some tools of maintenance were 
common to all. We also suspect that water was the medium of infection as described in some previous reports (Johnson \& Speare 2003, 2005). Bd is known to be highly infectious, and although the presence of this pathogen was not confirmed in Japan until December 2006, this does not rule out the possibility that $B d$ invaded Japan much earlier. Retrospective investigation will be necessary to identify the actual invasion time domestically.

It is not yet well understood how chytrid fungus kills frogs. However, it is thought to obstruct the physiological function of the frog's skin (cutaneous respiration, osmoregulation and local biological defense mechanisms) resulting in death if the skin is affected widely and severely enough (Berger et al. 1998, Daszak et al. 1999, Green \& Muths 2005). Furthermore, Voyles et al. (2007) suggested that $B d$ causes loss of electrolytes and osmotic imbalance by disrupting normal cutaneous function.

Prior to this report, $B d$ had been found to affect at least 200 amphibian species from the orders Anura and Caudata in all amphibian-bearing continents except Asia (Hyatt et al. 2007). It is believed that frog chytrid is one of the main causes of global declines in amphibian populations since the 1960s. Dramatic amphibian declines and extinctions emerged in the next decade or later (Daszak et al. 1999, Weldon et al. 2004). Japan is inhabited by a total of 58 species and 5 subspecies of amphibians, comprising 23 species of Caudata and 35 species and 5 subspecies of Anura. Of these, $84.1 \%$ are Japanese endemic species. Furthermore, in the native amphibian 'red data' list issued by the Japanese Ministry of the Environment in 2006 (www.env.go.jp/ press/file_view.php?serial=8931\&hou id=7849), 10 endangered or critically endangered species, 11 vulnerable species and 14 relatively threatened species were listed, representing a 1.8-fold increase, in terms of numbers of the amphibian population threatened, during the past $10 \mathrm{yr}$.

Although the case here reported concerned chytridiomycosis in a collection of captive, exotic frogs, the fact that $B d$ has been discovered in Japan raises serious concerns about the potential for introduction of $B d$ to native amphibians. In order to prevent this, captive frogs, especially exotic species or those with confirmed $B d$ infections, must not be released into the natural environment, and breeding water should be treated with fungicide prior to disposal.

Acknowledgements. This research was partially supported by The Promotion and Mutual Aid Corporation for Private Schools of Japan, Grant-in Aid for Matching Fund Subsidy for Private Universities.

\section{LITERATURE CITED}

Annis SL, Dastoor FP, Ziel H, Daszak P, Longcore JE (2004) A DNA-based assay identifies Batrachochytrium dendrobatidis in amphibians. J Wildl Dis 40:420-428

Berger L, Speare R, Daszak P, Green DE and others (1998) Chytridiomycosis causes amphibian mortality associated with population declines in the rain forests of Australia and Central America. Proc Natl Acad Sci USA 95: 9031-9036

Berger L, Speare R, Kent A (1999) Diagnosis of chytridiomycosis in amphibians by histologic examination. James Cook University, Townsville. www.jcu.edu.au/school/phtm/ PHTM/frogs/histo/chhisto.htm

Bradley GA, Rosen PC, Sredl MJ, Jones TR, Longcore JE (2002) Chytridiomycosis in native Arizona frogs. J Wildl Dis 38:206-212

Daszak P, Berger L, Cunningham AA, Hyatt AD, Green DE, Speare R (1999) Emerging infectious diseases and amphibian population declines. Emerg Infect Dis 5:735-748

Goka K, Okabe K, Yoneda M, Niwa S (2001) Bumblebee commercialization will cause worldwide migration of parasitic mites. Mol Ecol 10:2095-2099

Green DE, Muths E (2005) Health evalution of amphibians in and near Rocky Mountain National Park (Colorado, USA). Alytes 22:109-129

> Hyatt AD, Boyle DG, Olsen V, Boyle DB and others (2007) Diagnostic assays and sampling protocols for the detection of Batrachochytrium dendrobatidis. Dis Aquat Org 73: 175-192

Johnson ML, Speare R (2003) Survival of Batrachochytrium dendrobatidis in water: quarantine and control implications. Emerg Infect Dis 9:922-925

Johnson ML, Speare R (2005) Possible modes of dissemination of the amphibian chytrid Batrachochytrium dendrobatidis in the environment. Dis Aquat Org 65:181-186

Lips KR, Brem F, Brenes R, Reeve JD and others (2006) Emerging infectious disease and the loss of biodiversity in a Neotropical amphibian community. Proc Natl Acad Sci USA 103:3165-3170

> Longcore JE, Pessier AP, Nichols DK (1999) Batrachochytrium dendrobatidis gen. et sp. nov. A chytrid pathogenic to amphibians. Mycologia 91:219-227

Ota H (2000) Current status of the threatened amphibians and reptiles of Japan. Popul Ecol 42:5-9

- Skerratt LF, Berger L, Speare R, Cashins S and others (2007) Spread of chytridiomycosis has caused the rapid global decline and extinction of frogs. EcoHealth 4:125-134

Speare R, Berger L (2000) Global distribution of chytridiomycosis in amphibians. James Cook University, Townsville. www.jcu.edu.au/school/phtm/PHTM/frogs/chyglob.htm

Thompson JD, Higgins DG, Gibson TJ (1994) Clustal W: improving the sensitivity of progressive multiple sequence alignment through sequence weighting, position-specific gap penalties and weight matrix choice. Nucleic Acids Res 22:4673-4680

> Voyles J, Berger L, Young S, Speare R and others (2007) Electrolyte depletion and osmotic imbalance in amphibians with chytridiomycosis. Dis Aquat Org 77:113-118

Weldon C, du Preez LH, Hyatt AD, Muller R, Speare R (2004) Origin of the amphibian chytrid fungus. Emerg Infect Dis 10:2100-2105

> Young S, Berger L, Speare R (2007) Amphibian chytridiomycosis: strategies for captive management and conservation. Int Zoo Yearb 41:85-95

Submitted: February 14, 2008; Accepted: October 27, 2008

Proofs received from author(s): November 12, 2008 